\title{
To screen, or not to screen for SARS-Cov2
}

\author{
Adamson S. Muula
}

Editor-in-Chief, Malawi Medical Journal; School of Public Health and Family Medicine, College of Medicine, University of Malawi; Africa Center of Public Health and Herbal Medicine (ACEPHEM), University of Malawi

Email address: amuula@medcol.mw

One of the trappings, if not a burden, to Editors-in-Chief (EIC) of many medical journals is that one is expected to write editorials. Thus attempting to speak from the Mount, the EIC has the opportunity to identify one or more issues they think is/are important for the readership at that time or had been in the past or for the future. Such issues have included a summary of articles published in that particular issue or in some volume, happenings on the political or professional realm in the specific country, region, globally in the association or society that owns the journal. Sometimes EICs spend time highlighting changes to, or reminding (potential) authors the journal's policy. ${ }^{1}$ Not unexpected, EIC can also spend their time writing on petty issues that gods often have, just because they have the platform which mortals don't normally have. ${ }^{2}$ The EICs often indulge themselves in long sentences, many ideas in single paragraphs and absolve themselves from proper referencing etiquette. Editors-in-Chief may also use editorials to settle scores against real or perceived enemies, start controversies. They basically write as they please, sometimes with significant harm to themselves personally and professionally. In short, the editorial is a prime example of how not to write, unless of course you are an EIC yourself in which case you may be answerable only to the board (assuming it is still functional). Editorials can also be re/conciliatory. And (they said one should not start a sentence with "and") if the ask you to explain yourself on what you wrote on "that editorial that was against the government", you have your editorial independence to flash..."I am untouchable"....well, almost.

Medical journals, be they general or specialist and some in between, have understandably grabbed the opportunity to publish material related to the novel Severe Acute Respiratory Syndrome Corona Virus 2 (SARS- Cov 2), the "cause" of Corona Virus disease of 2019 (Covid-19). I intend to stroke my notoriety again to join former South African President Thabo Mvuyelwa Mbeki who argued that HIV was not "the" cause for AIDS. ${ }^{3}$ I also argue today that SARS-Cov 2 is not the cause of Covid-19. Simply, not everyone who is infected with SARS-Cov 2 develops the disease (Covid-19). The available literature has shown that individual who are obese, have diabetes, hypertension, chronic lung disease and other co-morbid conditions are more likely to develop severe and critical disease suggesting that SARS-Cov 2 in and of itself is insufficient to cause morbidity. To be sure, there are likely to be many other factors, presently unknown that lead to disease. Just like HIV, SARS-Cov 2 is one of the causes of Covid-19, but not the only one.

There are several different models that attempt to explain disease causation, for example, the Web of Causation ${ }^{4}$ model and the 1976 Rothman's sufficient-component cause model.
I was taught these models by Charles Poole (https://sph. unc.edu/adv_profile/charles-poole-scd/ and a co-author with Rothman on many epidemiologic/al methods papers) at the School of Public Health of the University of North Carolina at Chapel Hill. The sufficient-component model ${ }^{5}$ has what are known as "causal pies" just like sections of a pizza pie. Outcomes (such as diseases) are usually not caused by a single factor, but by a combination of exposures (component causes) that may occur minutes or decades apart. To develop the disease (the outcome), an individual must have accumulated all component causes (to complete the pie). In sum, the combination of these component causes (now a sufficient cause) is now able to cause the disease. Charlie (as we fondly called him) also warned us of models, and suggested that these are what they are, i.e., models. "Very few of you have models for spouses", I recall that was Charlie! So next time I am on television, I should cause a storm by denying that SARS-Cov 2 is the cause for Covid-19.

Covid-19 has brought on to the public platform discussions on isolation and quarantine (often with many television guests mixing the two and not knowing what is the precise technical meaning of either), disease screening and clinical diagnosis. The "testing race" where each country or jurisdiction wants to join by doing as many tests as possible, without knowing for what purpose that testing is aimed at, is interesting, if not unfortunate and regrettable. I must say that even the World Health Organisation (WHO) has fallen in the same trap of promoting more and more testing even when it is not clear what is the purpose of the screening. I will not even talk about mass or targeted screening, yet these are also considerations that public health departments must consider.

Let me quote verbatim from what the WHO says about screening (from: https://www.who.int/cancer/prevention/ diagnosis-screening/screening/en/): ${ }^{6}$ “Screening is defined as the presumptive identification of unrecognized disease in an apparently healthy, asymptomatic population by means of tests, examinations or other procedures that can be applied rapidly and easily to the target population. A screening programme must include all the core components in the screening process from inviting the target population to accessing effective treatment for individuals diagnosed with disease. Screening is a process - one that begins with invitation to participate and ends with treatment for appropriately identified individuals. An effective screening programme should meet the following criteria:

- Mechanisms for systematic invitation and follow-up for individuals identified by the screening test as having an abnormal finding (call and recall mechanisms); 
- Participation of over $70 \%$ of the target population to be screened;

- Necessary infrastructure and resources to offer the test periodically and to adequately diagnose and treat those found to have cancer or a precancerous lesion, and;

- Robust monitoring and evaluation framework to assure quality."

The section above was of course specific to cancers but the rest of the advice remains, at least so I believe. So the question we need to ask is: is widespread testing for SARS-Cov 2 justified when isolation (of those diagnosed with infection) and quarantine (of contacts of index cases and those suspected to have infection, however that is determined) are not possible? Are countries not supposed to create the infrastructure for isolation and quarantine before widespread testing is implemented? May be one starts from the end as many countries are doing. Test, test and test in order to learn that starting off with testing was not that clever in the absence of prior thoughts of how to deal with those who test positive or their contacts? I wish to ask readers who are familiar with the Covid-19 response in their own countries to assess whether the infrastructure, not just laboratory personnel and reagents, is available beyond a positive or negative test result. If we do not know what we will do after the positive test, how often are we going to be testing and to what extent other lifesaving public health interventions are going to be crowded out, should we go ahead with massive testing initiatives?

I have also found (from my Mount in the wilderness) that there are limited conversations on test sensitivity and specificity. I have not been able to observe much discussion on negative predictive value or positive predictive value (which Charlie said the correct terminology was predictive value negative or predictive value negative). There are of course some discussions of the performance of the different bodily fluids as to whether an individual tests positive or negative. Even when one is carrying the virus, it matters whether bronchoalveolar lavage, nasal, naso-pharyngeal, stool or other fluid is the focus of testing. It even gets interesting when one considers false positives and false negatives of the different tests in a context of different background SARS-Cov 2 prevalence.

In late 1960s (and yours truly was not even born at that time), the WHO commissioned James Maxwell Glover Wilson, then Principal Medical Officer at the Department of Health in London, England, and Gunner Jungner, then Chief of the Department of Clinical Chemistry at the Sahlgren's Hospital in Gothenburg (the capital of Västra Götaland County, Sweden to write a guidance report on Screening. The final report, published in 1968 entitled Principles and practice of screening for disease, ${ }^{7}$ should be basic reading for anyone studying public health and a reference document for those running public health departments. Even back then in 1968, Wilson and Jungner observed that "in theory, screening is an admirable method of combating disease ... [but] in practice, there are snags". They further observed that:

"The central idea of early disease detection and treatment is essentially simple. However, the path to its successful achievement (on the one hand, bringing to treatment those with previously undetected disease, and, on the other, avoiding harm to those persons not in need of treatment) is far from simple though sometimes it may appear deceptively easy." These words ring loud in 2020's world where massive SARS-Cov 2 testing programmes (or at least intentions) seem unguarded and being traded presumably in the public interest.

The SARS-Cov 2 pandemic is an opportunity for reflection and/or introspection in the field of public health practice. The extent to which a country deals with its own epidemic very much depends on the strength of its public health capacity in the competences as defined by the Association of Schools and Programmes of Public Health (no offence to other countries): Biostatistics; Environmental Health Sciences; Epidemiology; Health Policy and Management; Social and Behavioural Sciences; Communication and Informatics; Diversity and Culture; Leadership; Public Health Biology; Professionalism; Programme Planning and; Systems Thinking.

\section{References}

1. Fontanarosa PB. Guidelines for Writing Effective Editorials. JAMA. 2014;311(21):2179-2180. doi:10.1001/jama.2014.6535

2. Singh A, Singh S. What is a good editorial? Men Sana Mongr 2006; 4(1): 14-17.doi: 10.4103/0973-1229.27600

3. Muula A. South Africa's National Response to HIV and AIDS Treatment: Popular Media's Perspective. Croat Med J 2008 Feb; 49(1): 114-119. doi: 10.3325/cmj.2008.1.114

4. Krieger N. Epidemiology and the web of causation: has anyone seen the spider? Soc Sci Med 1994;39(7):887-903.

5. Rothman KJ. Causes. Am J Epidemiol 1976;104(6):587-592.

6. World Health Organisation. Screening. Retrieved on $24^{\text {th }}$ May 2020 from: https://www.who.int/cancer/prevention/diagnosis-screening/ screening/en/

7. Wilson JMG, Jungner G. Principles and practice of screening for disease , 1968. Retrieved on $24^{\text {th }}$ May 2020 from: https://apps.who.int/ iris/handle/10665/37650

53 